\title{
ANALYSIS OF REVERSE OSMOSIS FILTER PERMEABILITY
}

\author{
${ }^{1}$ Endre SALAMON, ${ }^{2}$ Zoltan GODA, ${ }^{3}$ Tamás BEREK \\ ${ }^{1,2}$ Institute of Water Supply and Environmental Engineering, Faculty of Water Sciences \\ National University of Public Service, Bajcsy-Zsilinszky u. 12-14, H-6500 Baja, Hungary \\ e-mail: ${ }^{1}$ salamon.endre@uni-nke.hu, ${ }^{2}$ goda.zoltan@uni-nke.hu \\ ${ }^{3}$ Department of Operations and Support, Faculty of Military Sciences and Officer Training \\ National University of Public Service, Hungária krt. 9-11, H-1101 Budapest, Hungary, \\ e-mail: berek.tamas@uni-nke.hu
}

Received 3 January 2018; accepted 17 April 2018

\begin{abstract}
Unsuitable feed water quality causes fouling and serious decrease in membrane permeability during the operation of reverse osmosis filters, which leads to costly operation and low contaminant removal efficiency. The purpose of the experiment was to create a detailed, yet simple calculation scheme, suitable for higher education and everyday pilot experiments. The obtained formulas were calibrated against measured results, while investigating the fouling of the membranes at different iron concentrations. Pressure losses on a reverse osmosis equipment with a permeate capacity of $100 \mathrm{~L} / \mathrm{h}$ were investigated for almost a year. Changes in permeability and cleaning methods were investigated with different feed water qualities.
\end{abstract} Fouling

Keywords: Reverse osmosis, Trans-membrane pressure, Reverse osmosis, Pressure loss,

\section{Introduction}

The basic requirement for the proper quality potable water is that it does not contain ingredients harmful for people; it needs to provide micro and macro elements necessary for human life and it has to satisfy the aesthetic needs of the consumer [1].

Despite the fact that the supply of water is complete in Hungary, about $40 \%$ of the population lives in settlements where the water supply, for different reasons, is not satisfactory.

Pollution of water supplies can influence water both on the surface of the ground and under the ground. Besides anthropogenic polluting activities the signs of the climate change are also visible in the characteristics of the future water supplies [2]. 
More and more often it is happening that extremely low levels of water come about together with periods of dryness. As a result, the amount of usable water declines. Smaller flow in the water bed results in deteriorating of the water quality and slower storage filling; the longer presence in the storages can induce further deterioration of the water quality [3].

Water supply is a complex process. Regulations emphasize, and experience also shows that in the case of quality deterioration it is necessary to take comprehensive measures. To establish sustainable water supply is also a requirement. To keep the water supply secure, besides building proper control regulations into the water supply, it is necessary to pay special attention to the security of some special activities that are necessary to ensure the proper quality of the supplied drinking water. Besides minimalizing the pollution of the raw water, the lessening or removal of the pollution guarantees the meeting of national and communal water quality guidelines and regulations. One of these regulations includes the properly sized and established water cleaning technology. Choice of the adequate water cleaning technology for the pollutants is of key importance to protect the health of the user.

In the case when the normal operation of the water supply system is not able to produce proper quality potable water or in case of cessation of the ability to operate, or when there is a havaria type of pollution is present, the water provided with alternative ways does not meet the requirements of potable water, due to their pollution, the provision of the population with potable water needs to be designed for a longer time. In this case mobile water cleaning equipment can be used. For this aim equipment, used all over the world, operating on the principle of the turned osmosis is of especially favorable characteristics. The advantage of the technology is that in case of emergency situation when the alternative water supply sources and other primarily mineable underthe- ground sources are not accessible then using this technology is possible to reach the on-the-ground water sources that can become easily polluted.

Reverse osmosis has become an affordable and widely applied solution. Its oldest and largest user is the food industry (for concentrating fruit juices and alcoholic beverages). But it can be used for desalinating water with lower salt content, i.e. brackish water. This latter application was considered to be its primary use in the 1970s over seawater desalination [4].

Different applications of the reverse osmosis before 1990 were experimental [4], [5], because costs and demands did not allow a large scale application in drinking water treatment. Industrial scale application for drinking water treatment started only after 2000, when strict regulations and increasing demands made it affordable. In Hungary, industrial scale application is still restricted to special water demands and temporary water supply applications [6]. Reverse Osmosis (RO) can be a very effective process as a small scale application, mainly in the field of industrial desalination [7]. Tough RO is ideal for temporary applications (in case of catastrophic events) [8], [9] these applications do not require long term analysis of membrane permeability. The reason behind this is that in these applications the RO membranes are usually protected with some sort of pre-treatment (ultrafiltration) [10]. Another consideration for emergency water supplies is that the long term fouling is not relevant, because the membranes can be replaced instead of cleaning. 
Nonetheless, preserving the permeability of the membranes is an important task for every operator. In order to achieve this, permeability must be calculated as precisely as possible based on the parameters available for operators. These parameters (pressure and flow-rate) are only measured outside of the membranes (before and after) as boundary conditions. The operators usually have no information about the real distribution of pressure along the membrane and they have to rely on some theoretical correlations when calculating the permeability.

It is important to describe the pressure distribution along the membrane filter with mathematical formulas, which are detailed enough to achieve the required precision, but they use only limited and easily measurable factors. Another important consideration is that they can be understood by operating personnel and BSc level students having only elementary hydraulic knowledge. A calculation like this is introduced here, and the mathematical model was calibrated with results obtained from a long term operation experiment of small-scale RO equipment. The effect of dissolved iron content on the rate of membrane fouling was also observed.

\section{Previous results}

Mathematical descriptions of the reverse osmosis process are available for a long time. However, these general scientific descriptions are focusing on the transport phenomena of solvents and dissolved materials [11]. Osmotic pressure model [12], concentration polarization model and Makardij-model [13] should be mentioned from the Hungarian literature. These models assess the membrane permeability on different levels of detail. The definition of the flux is generally:

$$
J=B\left(\Delta P_{T M}-\Delta \pi\right),
$$

where $\Delta P_{T M}$ is the trans-membrane pressure; $\Delta \pi$ is the osmotic pressure difference and $B$ is the permeability [14]. Other authors differentiate between the resistance due to concentration polarization and physical clogging [15], but they are not evaluated separately, only the overall resistance is considered in the calculations. Slater et al. successfully used this method to calculate multi-stage systems [16]. The main goal of the numerical models is to predict salt rejection and water chemistry behavior [17]. The other analyses of the reverse osmosis membranes exclusively use highly detailed computer simulations. The closest approach to the one described here is the system of partial differential equations published by Zhao et al., who considered the friction losses and used a finite difference method for calculations [18]. They suggested that steady state calculations can be used for design, while dynamic simulation is for optimizing process control. Friction losses and turbulence in the channels can also be a subject of computer modeling [19].

There are a large number of models describing different parameter values along spiral wound membranes. These parameters include salt rejection, osmotic pressure, concentration polarization, flow velocity and so on [20]. Some authors used finite element methods for calculations [21]. Other researchers presented models with detailed membrane spacer geometry for pressure loss calculations [22]. 
The most simplified calculation used and proved to be adequate for design and operation is the trans-membrane pressure calculated as the average of the feed and concentrate pressure. This sometimes corrected with the osmotic pressure and the pressure of the permeate side in cases they cannot be neglected [23].

\section{Definitions}

In order to define the permeability of a reverse osmosis membrane the following parameters were used:

- $\quad \operatorname{Flux}(J)$ : Flux of permeate (solvent) on the surface of the membrane. Usually given in Liters/square Meters/Hour, LMH $\left(\mathrm{L} \cdot \mathrm{m}^{2} \cdot \mathrm{h}^{-1}\right)$ units;

- Specific flux: flux induced by one unit of pressure, for example: $\mathrm{L} \cdot \mathrm{m}^{2} \cdot \mathrm{h}^{-1} \cdot \mathrm{Pa}^{-1}$ [5]. In practice $\mathrm{LMH} /$ bar units are used. Specific flux is considered as the membrane permeability here;

- Selective permeability: not to be confused with permeability, it is the removal efficiency for a selected dissolved salt;

- Specific head-loss $(S)$ : This parameter is used to calculate head-loss in conduits. Pressure loss is proportional to conduit length, specific head-loss and flow-rate squared. Calculating $S$ for a spiral wound membrane is somewhat problematic, because the spacers in thin membrane channels make formulas for simple pipe head-loss calculations obsolete;

- Spiral wound, cross-flow membrane: The membrane sheets and collector layers with spacers are wound around a perforated pipe. A detailed graphic representation can be found in the M46 Manual of water supply practices: 'Reverse osmosis and nanofiltration' in [24, pp. 15-16].

\section{Description of measurements}

Pressure and flow-rate measurements were made on a spiral wound-membrane. Flow paths, measurement points and picture of the equipment are shown in Fig. 1. Feed water pressure measured on manometer RO-P4, flow-rate measured on rota-meter ROF3. Flow-rates for the concentrate and permeate measured on rota-meters RO-F4 and RO-F6. For error check flow-rates are also determined based on water meter RO-V2. The concentrate pressure was read from manometer RO-P5.

In order to obtain a simple formula for permeability calculations, the model shown in Fig. 2 was used.

The spiral wound membrane can be considered as a pipe with a length of $L$ and a filter surface of $A$. At one end $Q_{0}$ flow-rate enters under $H_{0}$ pressure. The permeate leaves as a flow distributed along the length of the pipe. The specific permeate flow on a pipe element is $q$ and the overall permeating flow-rate is:

$$
Q_{p}=\int_{0}^{L} q(x) d x
$$




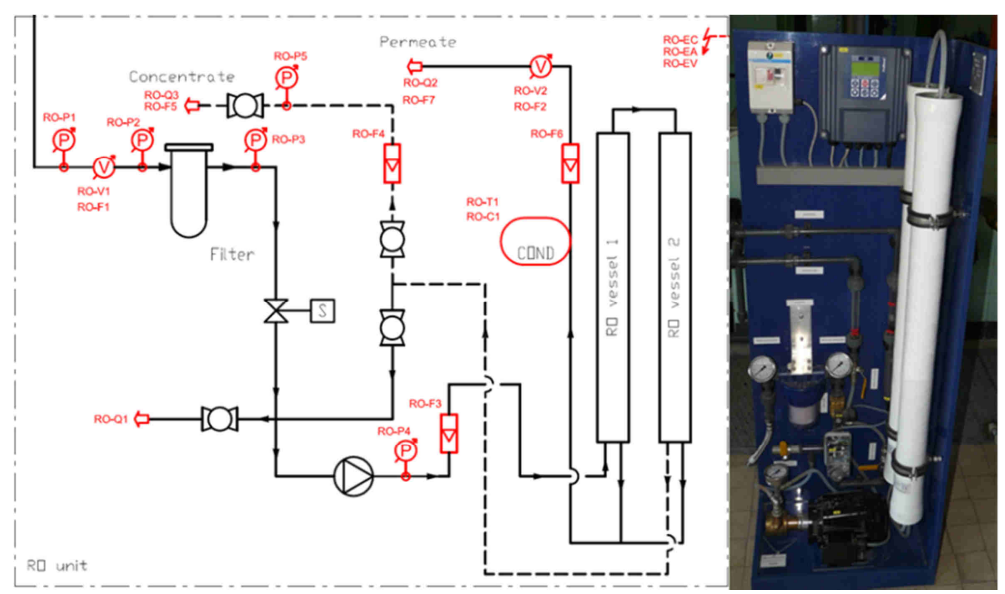

Fig. 1. Small scale RO equipment used for measurements

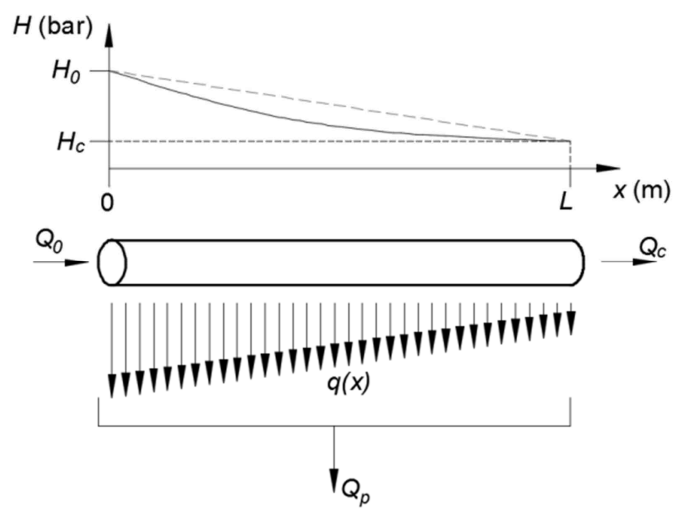

Fig. 2. Volume balance model for a membrane vessel

At the other end of the pipe the concentrate leaves with $H_{c}$ pressure, and from continuity $Q_{c}=Q_{0}-Q_{p}$.

For simplification it is assumed that the permeate side pressure is atmospheric at every point. In order to write a formula for the pressure distribution on the concentrate side, given by the $H(x)$ function, two formulas can be used. Equation (3) gives the pressure loss from the flow-rate on the concentrate side (friction losses),

$$
h_{v}=S Q^{2}
$$

The permeate flux can be written as:

$$
J=H \cdot C,
$$


where $H$ is the trans-membrane pressure and $C$ is the permeability defined as:

$$
C=\frac{1}{\mu K}
$$

where $\mu$ is the dynamic viscosity and $K$ is the membrane resistance. The specific permeate flow $q$ on a pipe element can be expressed using only known factors: pressure, permeability and geometric dimensions:

$$
q=J \cdot \frac{A}{L}=H \cdot C \cdot \frac{A}{L}
$$

Constant factors in equation (6) can be written as one single $c_{a}$ parameter representing the permeability:

$$
q=H \cdot c=H \cdot \frac{c_{a}}{L}
$$

Correlations between the measured pressure, flow-rate and the permeability and specific head-loss can be written in two equations. Equation (8) is for continuity and equation (9) is for the head-loss:

$$
\begin{aligned}
& \frac{d Q(x)}{d x}=-q(x)=-H(x) \cdot c=-H(x) \cdot \frac{c_{a}}{L}, \\
& \frac{d H(x)}{d x}=-S\left(Q_{0}-q(x)\right)=-S\left(Q_{0}-H(x) \cdot c \cdot x\right)^{2} .
\end{aligned}
$$

Equation (9) is a Riccati-type differential equation and even though it has an explicit solution, the resulting formula is too complex. To simplify the solution, the $c_{a}$ parameter is used instead of integrating the pressure dependent permeate flow $(c \cdot x)$ along the length of the membrane:

$$
\frac{d H(x)}{d x}=-S\left(Q_{0}-q(x)\right)=-S\left(Q_{0}-H(x) \cdot c_{a}\right)^{2} .
$$

These equations (8) and (10) can be solved for $H(x)$ and $Q(x)$ :

$$
H(x)=\frac{Q_{0}}{c_{a}}-\frac{1}{S c_{a}^{2}\left(x+C_{1}\right)},
$$




$$
Q(x)=-\frac{Q_{0}}{L} x-\frac{1}{S c_{a} L} \ln \left(S c_{a} L\left(x+C_{1}\right)\right)+C_{2} .
$$

Based on the boundary conditions in Fig. 2 the values for the integration constants $C_{l}$ and $C_{2}$ can be found:

$$
\begin{aligned}
& C_{1}=\frac{1}{\left(H_{0}-\frac{Q_{0}}{c_{a}}\right) S c_{a}^{2}}, \\
& C_{2}=Q_{0}+\frac{1}{S c_{a} L} \ln \left(\left|S c_{a} L C_{1}\right|\right) .
\end{aligned}
$$

During everyday operation the $Q_{0}$ flow-rate and the $H_{0}$ feed pressure can be measured. In addition the $Q_{c}, H_{c}$ concentrate feed and pressure, as well as the $Q_{p}$ permeate flow-rate can be measured and the unknown parameters $S$ and $c_{a}$ can be determined. $S$ represents the pressure loss in the concentrate side channels and $c_{a}$ represents the permeability of the membrane. Based on measured values the clogging of the concentrate side channels and the permeability can be assessed by solving the equations for $S$ and $c_{a}$.

\section{Results and discussion}

The parameters measured on the small scale RO equipment resulted in the time series shown on Fig. 3.

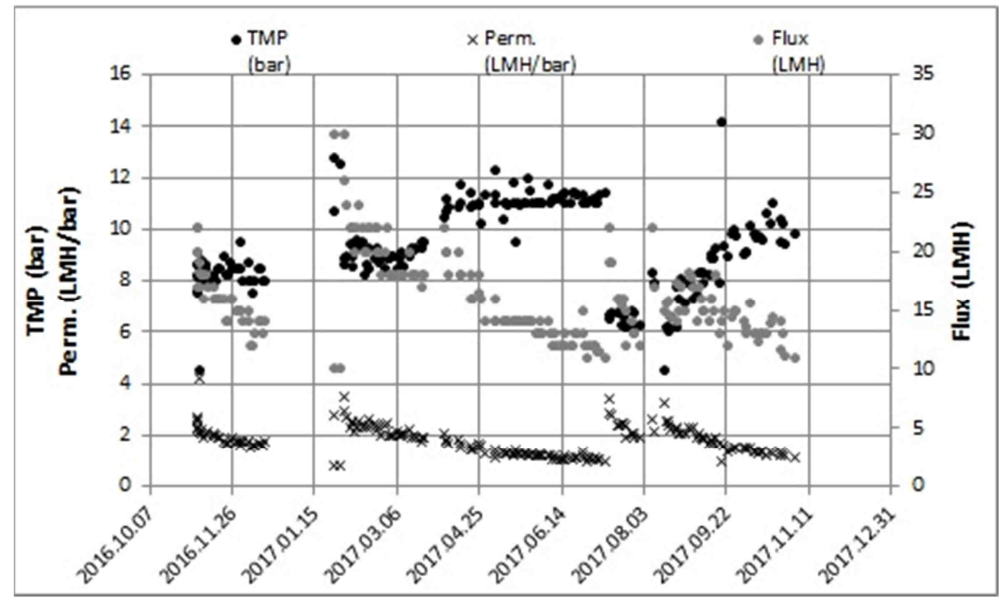

Fig. 3. Time series of measured parameters on RO membrane filter 
Based on operating conditions in January - July in 2017 the calculated values for the parameters are shown in Table I. In July, 2017 feed water with increased iron content $(0.5 \mathrm{mg} / \mathrm{L})$ were fed on the membranes. It resulted in higher fouling and a rapid decrease in permeability. Under these conditions the values in Table II were obtained.

The head-loss profile $(H(x)$ function) fitted on these results is shown in Fig. 4.

As expected the value of the parameter $c_{a}$ representing the membrane permeability turned out to be lower after the filter was operated with higher dissolved iron concentrations. However, the value for the parameter $S$ representing the friction loss in the concentrate channel gave a lower result. One explanation for this could be that pressure loss due to friction depends on the flow-rate itself and on the turbulence conditions. Since the flow-rates were different in the two operating conditions, the friction losses cannot be compared based on these kinds of calculations.

Table I

Measured and calculated values with less than $0.2 \mathrm{mg} / \mathrm{L}$ dissolved iron

\begin{tabular}{|c|c|c|c|}
\hline \multicolumn{2}{|c|}{ Mért értékek } & \multicolumn{2}{c|}{ Számított értékek } \\
\hline$Q_{c}(\mathrm{~L} / \mathrm{h})$ & 590 & $S\left(\mathrm{bar} \cdot \mathrm{h}^{2} / \mathrm{m} / \mathrm{L}^{2}\right)$ & $7 \cdot 10^{8}$ \\
$Q_{0}(\mathrm{~L} / \mathrm{h})$ & 700 & & \\
\hline$H_{0}(\mathrm{bar})$ & 12 & $c_{a}(\mathrm{~L} / \mathrm{h} / \mathrm{bar})$ & 5.625 \\
$H_{c}(\mathrm{bar})$ & 8 & & \\
\hline
\end{tabular}

Table II

Measured and calculated values with $0.5 \mathrm{mg} / \mathrm{L}$ dissolved iron

\begin{tabular}{|c|c|c|c|}
\hline \multicolumn{2}{|c|}{ Mért értékek } & \multicolumn{2}{|c|}{ Számított értékek } \\
\hline$Q_{c}(\mathrm{~L} / \mathrm{h})$ & 570 & $S\left(\mathrm{bar} \cdot \mathrm{h}^{2} / \mathrm{m} / \mathrm{L}^{2}\right)$ & $4 \cdot 10^{8}$ \\
$Q_{0}(\mathrm{~L} / \mathrm{h})$ & 620 & & \\
\hline$H_{0}(\mathrm{bar})$ & 12 & $c_{a}(\mathrm{~L} / \mathrm{h} / \mathrm{bar})$ & 2.5 \\
$H_{c}(\mathrm{bar})$ & 10 & \\
\hline
\end{tabular}

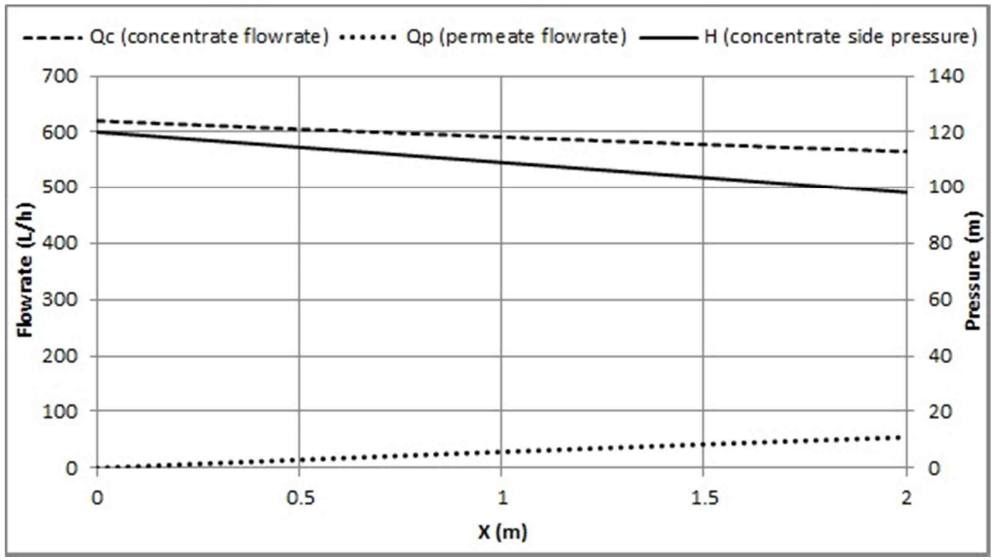

Fig. 4. Calculated head-loss and flow-rate profile at higher dissolved iron concentrations 
As it can be seen in Fig. 4 the head-loss profile approximates a linear tendency, even though the obtained formulas are non-linear. This way, the original approximation of the trans-membrane pressure as the average of the concentrate side pressure was justified.

The calculations described here are suitable for evaluating the membrane permeability, but for calculating friction losses, the data from everyday operation are insufficient. In order to assess the friction losses a measurement would be necessary with the permeate side completely closed. These kinds of tests are undesirable on most reverse osmosis filters, because feed pumps are designed for certain concentrate side throttle.

\section{Acknowledgements}

This work has been undertaken as a part of the H2020 AquaNES project.

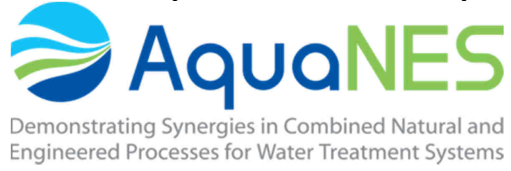

\section{References}

[1] Davidovits Zs., Berek L. Aquifer protection, drinking water safety, (in Hungarian) Bolyai Szemle, Vol. XXI, No. 2, 2012, pp. 7-26.

[2] Somlyódy L. Water management in Hungary: Current situation and strategic tasks, (in Hungarian) Köztestületi Stratégiai Programok, (Ed. Somlyódy L.) Magyar Tudomanyos Akademia, Budapest, 2011.

[3] Glatz F. Water management in the Carpathian basin, leadership summary (in Hungarian) MTA Társadalomkutató Központ, http://real.mtak.hu/35487/1/2009_Glatz_Vizgazdalkodas a_Karpat_medenceben_u.pdf (last visited 25 September 2015).

[4] Dobolyi E., Dobos F-ne. Practical application of the reverse osmosis principle in water management, (in Hungarian) Hidrológiai közlöny, Vol. 58, No. 3, 1978, pp. 122-130.

[5] Pernyeszi J., Gerlei I., Melenyecz J. Exceprts from military water treatment research (in years of 1970 and 1980), with special regard to the reverse osmosis, Part I, (in Hungarian), Haditechnika, Vol. 51, No. 4, 2017, pp. 6-12.

[6] Berek T., Dénes K., Dávidovits Zs. Water safety plans in military encampment systems, (in Hungarian), Hadmérnök, Vol. X, No. 2, 2015, pp. 108-121.

[7] Dolgosné Kovacs A., Lakner G. Multi stage solution for a flexible mobile water treatment technology - Case study, Pollack Periodica, Vol. 9, No. 2, 2014 pp. 99-110.

[8] Dávidovits Zs. Water supply of military missions, usage of Zenon equipment, (in Hungarian), Hadmérnök, Vol. VI, No. 2, 2011, pp. 37-46.

[9] Kállay E. Water supply of the Hungarian Defense Forces, with special regard to water treatment (in Hungarian), PhD Thesis, Nemzeti Közszolgálati Egyetem, 2013.

[10] Padányi J., Kállay E. New process equipment for water, (in Hungarian), Katonai Logisztika, Vol. 13, No. 2, 2005, pp. 190-201.

[11] Ghernaout D. Reverse osmosis process membranes modeling - A historical overview, Journal of Civil, Construction and Environmental Engineering, Vol. 2, No. 4, 2017, pp. 112-122. 
[12] Yahya R. Separation of ions with different charges with membrane nanofiltration (in Hungarian), PhD Thesis, Budapest University of Technology and Economics, 2010.

[13] Hodúr C. New trends in the utilization of wastes from food industry, (in Hungarian), DSc Thesis, Hungarian Academy of Sciences, Budapest, 2013.

[14] Kiss I. Alternative methods for the re-use of winery products with membrane technology, (in Hungarian), PhD Thesis, Corvinus University of Budapest, 2013.

[15] Kiss Zs. L. Effect of pre-treatment on filtration parameters during membrane filtration of thermal water and waters with oil content, (in Hungarian), University of Szeged, 2015.

[16] Slater C. S., Zielinsky J. M., Wndel R. G. Simulation of reverse osmosis processes concentrating industrial wastes, Journal of Environmental Science and Health, Part A: Environmental Science and Engineering, Vol. 27, No. 5, 1992, pp. 1175-1193.

[17] Sowgath M. T., Mujtaba I. M. Design of reverse osmosis process for the purification of river water in the Southern Belt of Bangladesh, Chemical Engineering Transactions, Vol. 61, 2017, pp. 1159-1164.

[18] Zhao T., Niu R., Su M., Anderson T. Steady state and dynamic modeling of RO desalination modules and system using EES, IEEE International Conference on Robotics and Automation, Shanghai, China, 9-13 May 2011, Paper 5980587.

[19] Karches T. Detection of dead-zones with analysis of flow pattern in open channel flows. Pollack Periodica, Vol. 7, No. 2, 2012 pp. 139-146.

[20] Jiang A., Ding Q., Wang J. Jianghzou S., Cheng W., Xing C. Mathematical modeling and simulation of SWRO process based on simultaneous method, Journal of Applied Mathematics, 2014, doi: 10.1155/2014/908569.

[21] Belkacem A., Kadi E. M. L., Belhamiti O. Mathematical modeling of reverse osmosis process by the orthogonal collocation on finite element method, Asian Journal of Applied Sciences, Vol. 1, No. 1, 2008, pp. 1-18.

[22] Srivathsan G. Modeling of fluid flow in spiral wound reverse osmosis membranes, $P h D$ Thesis, University of Minnesota, Minneapolis, 2013.

[23] Kucera J. Reverse osmosis: Design, processes an application for engineers, Wiley, 2010.

[24] Valentine M. (Ed.) Reverse osmosis and nanofiltration, American Water Works Association, Vol. M46, 2007. 